\title{
DEZ ANOS DEPOIS: O VOO DO PASSARINHO, A SABEDORIA DO BEIJA-FLOR
}

\author{
José Ribamar Bessa Freire ${ }^{l}$ (D) \\ Ana Paula da Silva ${ }^{2}$ (D)
}

Te mandei um passarinho / Patuá miri pupé / pintadinho de amarelo / iporanga ne iaué. Couto de Magalhães (1876, p. 41)

RESUMO: O presente artigo aborda a produção diferenciada de materiais didáticos e propostas museológicas concebidas a partir de diferentes açóes do Programa de Estudos dos Povos Indígenas da Faculdade de Educaçáo da Universidade do Estado do Rio de Janeiro (PROÍNDIO-UERJ) em 26 anos de existência, propondo estimular e difundir a sensibilidade e o conhecimento acerca dos indígenas, contribuindo, assim, para a formação, não apenas, de professores e educadores da educação infantil à pós-graduação. A análise inicialmente focaliza três experiências de editoração de livros, posteriormente recupera alguns exemplos de mostras expográficas que abordaram a temática dos povos indígenas no Rio de Janeiro e, por último, tece algumas reflexóes sobre o público e suas interaçóes. Tratase de uma reflexão, ainda que parcial, da contribuição do PROÍNDIO na implementação da Lei no 11.645 .

Palavras-chave: Formação de professores indígenas no Rio de Janeiro. Interculturalidade. Lei no 11.645/08. Material didático.

\footnotetext{
${ }^{1}$ Universidade Federal do Estado do Rio de Janeiro - Rio de Janeiro (RJ), Brasil. E-mail: bessa_18@hotmail.com

${ }^{2}$ Universidade do Estado do Rio de Janeiro - Rio de Janeiro (RJ), Brasil. E-mail: anapproindio@gmail.com.
}

DOI: $10.1590 / C C 0101-32622019217159$ 


\title{
Ten years later: the birdie's light, the hummingbird's wisdom
}

\begin{abstract}
The present paper comments on the differentiated production of didactic materials and museological proposals conceived from different actions of PROÍNDIO-UERJ, in 26 years of existence, proposing to stimulate and spread the sensitivity and knowledge about the indigenous people. Thus, contributing to the formation, of not only teachers and educators from Children Education to post-graduation. The analysis initially focuses on three book publishing experiences, and then retrieves some examples of expository samples that approached the theme of indigenous peoples in Rio de Janeiro, and finally comments on some reflections on the public and their interactions. This is a reflection, albeit a partial one, of the contribution of PROÍNDIO in the implementation of Law 11.645 .
\end{abstract}

Keywords: Training of indigenous teachers in Rio de Janeiro. Interculturality. Law No. 11.645/08. Didactic Material.

\section{INTRODUÇÃO}

A

$s$ duas reclamaçóes mais frequentes dos professores em relação à implementação da Lei no 11.645/2008 (BRASIL, 2008) é a de que, em primeiro lugar, os cursos de Pedagogia não oferecem formação específica sobre as culturas indígenas e sua história e, em segundo, a de que náo existe material didático ou paradidático adequado para ser usado em sala de aula dentro dos objetivos da lei. Tais objeçóes são procedentes, como já assinalou o antropólogo Carlos Alberto Ricardo (1995, p. 30), para quem "o público leigo interessado em conhecer mais a respeito dos índios está diante de um abismo cultural e terá de se contentar com uma bibliografia rala, quando náo preconceituosa ou desinformada".

No entanto, nos últimos dez anos podemos constatar aqui e ali alguns avanços ainda modestos que são o foco deste artigo. Aborda- 
remos experiências desenvolvidas pelo Programa de Estudos dos Povos Indígenas da Faculdade de Educação da Universidade do Estado do Rio de Janeiro (PROÍNDIO-UERJ), em parceria com variadas instituiçóes, para a difusão e a valorização das culturas indígenas. As ações permitiram, entre outros resultados, a criação no curso de Pedagogia da disciplina eletiva Educação Indígena: Processos Próprios de Aprendizagem, oferecida a diferentes licenciaturas da UERJ, exposiçóes, mostras de filmes etnográficos, além da elaboração de três livros sobre o tema. Trata-se de avaliar em que medida tais experiências contribuíram para a implementação da lei nos últimos dez anos.

\section{OS LIVROS}

Os três livros idealizados com a participação do PROÍNDIO-UERJ, criado em 1992, visavam oferecer uma alternativa aos manuais didáticos "que ainda tratam os índios, suas sociedades e seu papel na história, a partir de formulaçóes esquemáticas e pressupostos ultrapassados", conforme avaliação da antropóloga Aracy Lopes da Silva e Grupioni (1995, p. 16).

Construir uma alternativa à tal bibliografia pressupóe a existência de um saber histórico, antropológico e etnolinguístico produzido por especialistas, capaz de alimentar textos de divulgação direcionados a um público de não iniciados. Em tal contexto é que se situa a pesquisa realizada ao longo de dois anos (1992-1994) pela UERJ em parceria com a Universidade de São Paulo (USP) para identificar e mapear a documentação sobre indígenas em 25 grandes arquivos da cidade do Rio de Janeiro, num projeto coordenado nacionalmente pelo historiador John Monteiro e concebido com a participação da antropóloga Manuela Carneiro da Cunha (MONTEIRO, 1994). Esse levantamento foi complementado, em 1995, com pequenos arquivos paroquiais, municipais e cartoriais de 15 municípios do médio Paraíba e do norte fluminense, num projeto desenvolvido através de convênio da UERJ com o Ministério da Educação e Cultura (MEC) e com o Fundo Nacional de Desenvolvimento da Educação (FNDE) (FREIRE, 1995; 1996). Parece oportuna uma breve descrição de cada um dos três livros. 


\section{PRIMEIRO CONTEXTO}

Documentos encontrados nos arquivos, trabalhados criticamente, enriqueceram o primeiro livro Aldeamentos Indígenas do Rio de Janeiro (FREIRE; MALHEIROS, 2009), que contém cem páginas, com ilustraçóes coloridas de viajantes pertencentes às coleçóes da Biblioteca Nacional. Está dividido em duas partes:

- "Os índios do Rio de Janeiro e suas aldeias de origem" localiza os diferentes povos do litoral fluminense, as aldeias onde moravam, suas línguas e informaçooes etnográficas de como viviam tanto aqueles do litoral pertencentes à família linguística Tupi-Guarani como os da família Puri no Vale do Paraíba;

- " “ "Os índios catequizados e as aldeias de repartição" apresenta um panorama do processo colonial, a organização do trabalho compulsório dos indígenas em regime de escravidão ou fornecido pelos chamados "índios de repartição", além de acompanhar a catequese e a usurpação de terras, a formação das principais aldeias, transformadas depois em vilas e povoados, com um destaque para os indígenas na Corte do Rio de Janeiro no século XIX.

Cada uma das partes traz leituras complementares com transcrições de trechos de documentos históricos, uma cronologia do período e referências bibliográficas destinadas aos professores interessados em aprofundar o tema. A sua primeira edição, ainda em 1997, estava destinada a apoiar os ensinos fundamental e médio, atendendo às exigências dos Parâmetros Curriculares Nacionais $(\mathrm{PCN})$. Foi reeditado pela EdUerj, em 2009, depois da vigência da Lei $n^{\circ} 11.645 / 2008$, em tiragem de 10 mil exemplares, com apoio da Prefeitura do Rio de Janeiro para distribuição em todas as escolas do município. Seu ponto de partida se fundamenta na premissa de que estudar as culturas indígenas não se limita a conhecer "o outro", "o diferente", mas implica conduzir as indagaçóes e reflexóes sobre a própria sociedade em que vivemos. A sociedade brasileira se revela plenamente no relacionamento com os povos indígenas, que constituem indicadores extremamente sensíveis da natureza da 
sociedade que com eles interage. Nas oficinas realizadas em parceria com secretarias municipais e estaduais ${ }^{1}$, os professores manifestaram a necessidade de aprofundar o período anterior à chegada dos portugueses com os resultados das pesquisas arqueológicas, que são apenas mencionadas (DIAS, 1998).

\section{SEGUNDO CONTEXTO}

O segundo livro, Te mandei um passarinho: prosas e versos de indios no Brasil (MACIEL et al., 2007), foi elaborado no Rio de Janeiro um ano antes da promulgação da lei. Apresenta textos e ilustraçóes de escritores e artistas plásticos, todos eles indígenas, pertencentes a mais de 30 etnias de todas as regióes do Brasil. A iniciativa respondeu a um edital do MEC, visando produzir um livro na série "Literatura para Todos", destinado a (neo)leitores do Programa de Educação de Jovens e Adultos (EJA). A seleção dos textos foi feita a partir dos cursos de formação de professores indígenas ministrados em diferentes regióes do Brasil e de material de arquivo. Sua organização ficou a cargo de uma equipe de quatro professores não indígenas, sendo a coordenação temática de responsabilidade do PROÍNDIO.

O livro, de 82 páginas, está dividido em três partes:

- "Histórias moram dentro da gente", com trechos de diferentes narrativas míticas explicando a origem do mundo;

- " "Esta terra tem vida", com a visão de várias etnias sobre sua relação com a natureza, de interesse para a educação ambiental;

- "Por que isso se passa comigo", que aborda a questão existencial, as relaçóes pessoais e sociais, a questão da memória e da resistência indígena.

No fim, descreve brevemente a situação atual das etnias dos autores, além de apresentar um pequeno glossário com a explicação de termos de línguas indígenas usadas nos textos.

O título inspirou-se no poema bilíngue português Nheengatu, recolhido no Pará por Couto de Magalhães, em 1865, publicado em 
O Selvagem (COUTO DE MAGALHÁES, 1876), quando o Nheengatu ou Língua Geral ainda era falado por amplas parcelas da população da Amazônia (COUTO DE MAGALHÂES, 1876, p. 41). A tradução do poema em Língua Geral, que hoje se faz necessária, foi feita com base no dicionário de Nheengatu de Ermano Stradelli, a partir de sugestóes dos índios Guarani: "Te mandei um passarinho/dentro de uma cestinha/pintadinho de amarelo/e bonito como você" (FREIRE, 2009b, p. 322).

A produção gráfica e editorial é extraordinariamente impactante, com ilustraçóes coloridas feitas pelos indígenas. Embora pronto para a edição, por razões orçamentárias e burocráticas o livro não foi impresso, mas sua versão digital circula entre os professores.

\section{TERCEIRO CONTEXTO}

O terceiro livro, Mainoĩ rapé: o caminho da sabedoria, foi publicado em sua versão impressa um ano depois da promulgação da lei. Não se trata mais de um passarinho genérico, mas do beija-flor, denominado pelos Guarani de Mainỗ, que para eles simboliza a sabedoria. É um livro bilíngue, em língua guarani e português, com desenhos e textos produzidos quase sempre pelos próprios indígenas do curso de formação de professores Kuaa Mbo'e: Conhecer, Ensinar (Protocolo Guarani), distribuídos em 78 páginas. Produzido pelo Centro Nacional de Folclore e Cultura Popular (CNFCP) em parceria com a UERJ, o tamanho do livro e das letras foi decidido pelos indígenas. Traz dados de demografia histórica sobre a população indígena em 1500, mapas da distribuição dos guarani em território brasileiro e da América do Sul para situá-los no século XXI.

O texto apoiou-se no projeto de pesquisa e fomento Cestaria Guarani: Narrativas Orais do Artesanato nas Aldeias do Rio de Janeiro, com recursos do Programa Monumenta, em parceria com o PROÍNDIO e seu projeto itinerante De Mala e Cuia. A ideia era "construir um instrumento dinâmico e lúdico, com informaçóes e linguagens que dessem conta de tratar da cultura guarani para leitores de diferentes níveis de aprendizado nas escolas bilíngues" (TELLES, 2009, p. 5), mas 
também nas escolas da rede pública do sistema nacional de educação. Seu ponto de partida foi o provérbio Igbo, da Nigéria, que proclama: "Enquanto os leóes não tiverem seus próprios historiadores, as histórias sempre glorificarão o caçador". O livro é uma tentativa de dar voz a quem foi "caçado", rompendo com o monopólio do "caçador" (FREIRE, 2009a, p. 6).

O alunos e o professor lá encontram narrativas dos Guarani sobre a forma de construir suas casas concebidas por arquitetos descalços, sobre a agricultura, as comidas, a caça e a pesca, uma taxonomia de animais, aves domésticas e plantas, a arte e a cestaria, a religião, a relação com a natureza, as festas e danças, a língua e a escola bilíngue, o uso do computador, as narrativas míticas, como eles namoram e casam, a mulher e a criança Guarani, os brinquedos, a ciência, a astronomia e algumas narrativas, quase todas coletadas entre os professores bilíngues das aldeias do Rio de Janeiro, Rio Grande do Sul, Paraná, Santa Catarina e Espírito Santo.

\section{FORMAÇÃO DE PROFESSORES}

Os três livros são trabalhados a cada semestre na disciplina Educação Indígena com alunos do curso de Pedagogia e de diferentes licenciaturas da UERJ, mas também em oficinas realizadas em distintas regióes do Brasil com professores das redes estadual e municipal de ensino. Vamos destacar aqui o uso em sala de aula do livro Te mandei um passarinho e avaliar em que medida contribuiu com os objetivos da lei, a partir do depoimento de professores, que opinaram sobre as construçóes de sentidos na interação com o texto e as ilustraçóes.

Vale salientar, previamente, que vários testes de recepção foram feitos, entre outros, com os participantes da Jornada Cultural da Ilha do Marajó, em Soure, Pará, com os guarani do curso de formação Protocolo Guarani, com as presidiárias de uma penitenciária feminina da Bahia e com professores da rede de ensino do Rio de Janeiro. Em todos eles foram registradas algumas reaçóes similares à de Couto de Magalhães (1876), maravilhado com as histórias "originais e belas" dos povos indígenas, que a elas se refere como um "verdadeiro colar de pedras finas, tanto pelo 
espírito e animação do enredo, como pelo laconismo, sobriedade das cenas e clareza" (COUTO MAGALHÃES, 1876, p. 41). Ele não hesita em situá-las dentro do quadro da literatura universal, dizendo que estão no mesmo nível que as fábulas de Esopo, Fedro e La Fontaine.

Após a promulgação da Lei no $11.645 / 08$, apresentamos a versão digital desse livro em colóquios, seminários, encontros, cursos, palestras e oficinas para professores de diferentes cidades do Brasil. Começamos em 2008 no Rio de Janeiro, Manaus, Tabatinga, Benjamin Constant e Barcelos (no Amazonas), Belém (Pará) e Campo Grande (Mato Grosso do Sul). Percorremos várias cidades do Brasil nos últimos dez anos, com exposições também fora do país, na Colômbia, no Equador e no Peru.

Nos anos seguintes, durante eventos quase sempre destinados a professores das redes estaduais de ensino, o livro foi apresentado em Rio Branco (Acre), São Gabriel da Cachoeira (Amazonas) e Goiânia (Goiás) (2009), assim como para professores de EJA em cursos organizados pela Secretária Municipal de Educação do Rio (2010 e 2011), no curso de formação de professores do Projeto Igarité em Rio Preto da Eva, no Amazonas (2012), no Curso de Gestão Territorial e Ambiental da Universidade Federal de Roraima (2012), em Foz do Iguaçu (2014), em encontro com professores e alunos do Colégio Pedro II - Centro, Rio de Janeiro (2015) e até na 69a Reunião da Sociedade Brasileira para o Progresso da Ciência (SBPC) em Belo Horizonte (2017), quando discutimos a invisibilidade das línguas indígenas no Brasil.

Professores solicitaram, em quase todos os eventos citados, e lhes foi concedida uma cópia digital do livro para trabalhar em sala de aula, dentro do contexto da Lei $n^{\circ} 11.645 / 2008$, conscientes de que os textos ali apresentados, elaborados por autores indígenas, estavam em formato que convencionamos denominar impropriamente de prosa ou de verso, talvez por dificuldade de classificar aqueles gêneros literários.

O livro usado em várias disciplinas ministradas em diversas licenciaturas e cursos de Pedagogia, Museologia e Biblioteconomia mereceu avaliaçáo escrita dos alunos da UERJ e da Universidade Federal do Estado do Rio de Janeiro (UNIRIO). Cerca de 200 comentários constam de uma edição artesanal com tiragem de 100 exemplares, cujo título En- 
contrei um passarinho foi inspirado no texto de uma aluna da licenciatura em Ciências Sociais. Um exemplar foi entregue a cada um dos autores presentes no III Encontro de Escritores e Artistas Indígenas realizado na UERJ em 2011, com um prefácio que problematiza o processo de transferência para o registro escrito das narrativas orais:

O papel da escrita, que confere "prestígio", não é, porém, guardar os ossos do som no livro, a letra morta em um caixão. Não se trata de uma "escrita funerária", destinada a sepultar no túmulo línguas já condenadas, inapelavelmente, a desaparecer. Essas línguas não estáo moribundas, apenas anêmicas. O livro funciona, entáo, como um hospital, onde a palavra, depois de injetada com sangue novo, volta a circular, revitalizada, no universo da oralidade. Livremente. Como um pássaro (PROÍNDIO, 2011, p. 2).

O escritor e teólogo Leonardo Boff também deu seu depoimento sobre o livro Te mandei um passarinho na abertura dos comentários dos alunos:

Gostei muito do livro, das gravuras, pinturas e ilustraçóes e dos poemas que você me enviou através de minha irmã Lina. Fiz algo semelhante há anos, "O Casamento do Céu com a Terra" com 30 mitos indígenas contados na linguagem atual. $\mathrm{O}$ livro é bem ilustrado com motivos da cultura indígena. Fiz também um suplemento sobre onde estáo e que contribuiçóes deram e dão à cultura nacional e mundial. De todas as formas agradeço a gentileza e passarei adiante esta bela produçáo de nossos povos originários. Com um abraço fraterno, Leonardo Boff (apud PROÍNDIO, 2011, p. 3).

Talvez a avaliação da aluna Bruna de Moura Pereira, responsável pelo título dos comentários, sintetize as observações feitas por seus colegas sobre a contribuição do livro em sua formação: 
"Encontrei um passarinho". Escrever um texto acadêmico sobre como um graduando complexificaria o material literário indígena seria tarefa rasa. Pensar em um livro é algo de importância universal. Sem jamais ter saído da sua cidade é através dos livros que um habitante da zona da mata de Pernambuco, por exemplo, pode conhecer as esculturas gregas, as máscaras africanas ou os animais do Peru. Por que náo conhecer os mitos de origem, os remédios e as cantigas de ninar de povos indígenas? Por que não entender como legítima a vontade de índios fazerem livros? Por que achar que a palavra escrita fará a voz se calar? (apud PROÍNDIO, 2011, p. 20).

As leituras de Bruna foram complementadas por sua visita à exposição Floresta de Livros, organizada pelo PROÍNDIO, na qual os visitantes puderam folhear cerca de cem livros usados nas escolas indígenas do Brasil.

Circular na "Floresta de Livros", já adulta, foi uma experiência renovadora, eu que acreditava que a preservação da tradição oral se dava a partir da não transformação da tradicional forma de repassar narrativas. Levar meu filho em plena infância para circular na "floresta de livros", sendo ele um apaixonado pela literatura e que através do olhar inocente percebeu aqueles livros como tantos outros vindos de todo o planeta, foi uma experiência inspiradora (PROÍNDIO, 2011, p. 20).

A experiência direta com livros — didáticos e literários — produzidos por indígenas, na época pouco conhecidos na sociedade brasileira, contribuiu para enriquecer e marcar a formação da estudante. Para Bruna,

A minha compreensão de preservação da cultura fluiu para além do ideal utópico de pensar o índio guardado na mata, o negro jamais contrabandeado e de apagar a vergonha da devastaçáo que o branco co- 
meteu. A "floresta de livros" reforçou algo que eu já havia discutido na academia, mas não havia sentido na alma: a possibilidade de juntar o melhor dos mundos, de trocar ferramentas para construir um futuro mais harmônico e, no caso da palavra escrita, náo apenas preservar internamente um grupo, mas poder compartilhar com o mundo a dor e a beleza de ser tribal. Em tempos onde muitas línguas estáo mortas, muitos índios assassinados, muitas matas destruídas, muitos mitos desconsiderados, em tempos onde muitas vezes o minério vale mais que a vida, uma floresta de livros mandou um passarinho para o meu coraçáo (apud PROÍNDIO, 2011, p. 20-21).

Organizamos ainda exposições outras especificamente sobre a realidade dos povos indígenas no território fluminense, conforme veremos a seguir.

\section{INFORMAR, SENSIBILIZAR, ENCANTAR}

Desde sua criação, o Programa de Estudos dos Povos Indígenas vem desenvolvendo estudos e produzindo conhecimento sobre as distintas realidades dos indígenas no território fluminense e no Brasil, valorizando suas práticas culturais, saberes, memórias e patrimônios, disseminando a importância e as contribuiçôes desses povos à cultura e à história brasileira, por meio do ensino, pesquisa e extensão universitária. Inscrevendo as temáticas das sociedades indígenas na educação pública (antes mesmo da promulgaçáo da Lei no 11.645/08), o PROÍNDIO-UERJ promoveu ainda diferentes propostas museológicas com parcerias variadas, em razão de constituírem-se uma das principais formas de aproximação do público notadamente escolar, universitário e especializado, mas também visitantes outros.

Apresentamos, desse modo, alguns dados históricos extraídos de nossas trajetórias próprias como coordenador e como pesquisadora do PROÍNDIO-UERJ ${ }^{2}$ - recorrendo sempre que possível ao arquivo institucional, alfarrábios e memórias. Adotando distintas estratégias de 
diálogo com o público, montamos principalmente exposições temporárias e itinerantes, abarcando temáticas variadas para discutir a presença e o protagonismo indígena no processo de construção das sociedades coloniais e pós-coloniais. Tecendo os fios do passado e do presente, na primeira década de atuação do programa, as mostras enfatizavam imagens, discursos, testemunhos, perspectivas indígenas presentes em documentos históricos de naturezas diversas, tais como: crônicas, iconografias, cartas e manuscritos dos primeiros séculos da conquista.

Com essa preocupação, organizou-se a mostra As Primeiras Imagens da Conquista (1994), dedicada às ilustrações de Felipe Guamán Poma de Ayala. Membro de respeitados clâs indígenas da região atual de Ayacucho (Peru), o indígena escreveu Nueva Corónica y buen gobierno, originalmente uma carta endereçada ao rei Felipe III, com 1.200 páginas e 398 desenhos (também de sua autoria), em que o autor, com base em sua lógica própria de organização do tempo e de suas memórias, nos oferece um relato singular em toda a América indígena (FREIRE, 1992; SILVA, 2016). Para executar seu projeto, Guamán Poma viajou por diferentes regióes do Peru, descrevendo paisagens, animais e plantas, registrando importantes dados etnográficos e linguísticos das populaçóes dos Andes peruano, denunciando os impactos da colonização espanhola às sociedades andinas (FREIRE, 1992). A exposição itinerante pode ser vista no Rio de Janeiro, Juiz de Fora (Minas Gerais) e em Manaus (Amazonas).

Seguindo o eixo condutor delineado, "Os viajantes e a iconografia indígena do Rio de Janeiro no século XIX"3 (1995, 1997) apoiou-se num conjunto de imagens produzidas por naturalistas, cientistas de nacionalidades distintas, que registraram diversas realidades desses povos no Oitocentos. O intuito da exposição era levar ao público a multiplicidade de narrativas submersas a elas associadas, pois as iconografias, embora conhecidas do público (em certo sentido banalizadas nos livros didáticos), seguiam pouco problematizadas. É preciso dizer que nossas primeiras mostras expositivas foram marcadas pelo Projeto Guia de Fontes para a História Indígena e do Indigenismo em Arquivos Brasileiros. Nesse sentido, o encontro de documentos históricos produzidos direta ou indiretamente sobre/por indígenas nos possibilitou desconstruir clássicas interpretaçóes sobre o Brasil, destacando os povos indígenas como agentes históricos. 
A carta (sem data, provavelmente escrita no fim do século XVII) de André Soares de Souza ${ }^{4}$ documentando a participação de indígenas na construção do Aqueduto Carioca, atual Arcos da Lapa (FREIRE; MALHEIROS, 2009), além de diversos manuscritos que registram a vinda de embaixadas indígenas para a Corte no século XIX - com objetivos, entre outros, de reivindicar seus direitos - conforme pesquisas recentes (SILVA, 2016), são notórios exemplos do protagonismo indígena e possibilitam escrever novos capítulos da nossa história. Perspectivas até então desconhecidas para a maioria dos habitantes do Rio de Janeiro, do país, abordadas na exposição Tem Índio no Rio. Inaugurada em 1999, a mostra convidou o espectador a viajar entre o passado fluminense indígena e o universo Guarani do presente, enfatizando a marcante presença dessas sociedades no estado (PROÍNDIO, 1999). Itinerante, a exposição percorreu os municípios de São Gonçalo, Casimiro de Abreu e Campos dos Goytacazes, territórios onde os Puri, Coroado e Coropó viviam de acordo com seus jeitos próprios de ser e estar no mundo até o século XIX (FREIRE; MALHEIROS, 2009).

Por outro lado, nas décadas seguintes, as exposiçóes montadas no Rio de Janeiro priorizaram a população indígena aqui existente. Sendo assim, focalizamos nos guarani (na época único povo aldeado no estado) — notadamente sua arte —, mas discutimos temas abrangentes como a educação escolar e os saberes indígenas, interculturalidade, infância e literatura indígena, aspectos muito pouco evidenciados nos espaços museológicos e galerias de arte não especializados do estado. Espaço escolar nas aldeias, oralidade e interculturalidade foram abordados na mostra fotográfica A Escola Indígena: Uma Experiência Intercultural (2000 e 2002). Já a arte guarani e suas transformaçóes no tempo nortearam as mostras: Artesanato Indígena: Artesanato Guarani Mbyá do Rio de Janeiro (2003), Arte Guarani Mbya: Fotos, Objetos, Produção Bibliográfica (2004) e Trançando Identidades: os Guarani do Rio de Janeiro (2005).

Fugindo do convencional e sempre atentos aos pleitos dos povos indígenas, buscamos refletir sobre as novas tecnologias da memória, cada vez mais presentes na vida cotidiana de muitas comunidades, entre elas a escrita e a literatura produzida por escritores e artistas indígenas. Afinal, muito se discute ainda sobre os impactos da escrita na oralidade 
e a apropriação dessa tecnologia por sociedades tradicionalmente orais. Assim sendo, a transformação do oral em palavras foi o ponto de partida para "Sem livros indígenas ou cem livros indígenas" (2008) e "Florestas de livros" (2009), pois nosso desejo era enfatizar que "há uma literatura escrita por indígenas; há uma identidade nessa produção literária; há uma demanda crescente por esse tipo de escrita. Isso é um fato notado a partir dos últimos 20 anos", conforme destacou o escritor Daniel Munduruku (2018).

Percorrendo os caminhos incertos e cheios de esquecimento da memória, lembramo-nos dos três encontros de escritores e artistas indígenas, que organizamos na UERJ (campus Maracanã) em parceira com Eliane Potiguara, Ailton Krenak, Daniel Munduruku, Olívio Jekupe, o saudoso Manoel Moura Tukano e tantos outros escritores, que vinham das florestas, das cidades trazendo poesia, arte, estética, saberes, originalidade, fúria, indignação. Múltiplas vozes, sensibilidade à flor da pele. Ver, conhecer, ouvir e ler, verbos que traduzem nossa estratégia de incluir na vida (não apenas nos currículos) dos nossos alunos a relevância dos povos indígenas para o Rio de Janeiro e o país, contribuindo na formação de cidadãos conscientes, futuros educadores.

Marcando nosso compromisso com a valorização e a difusão de conhecimento sobre a diversidade sociocultural e linguística dos povos indígenas no estado, montamos O Rio de Janeiro Continua Índio (2015) e participamos da curadoria e pesquisa de Djá Guata Porá, realizada no Museu de Arte do Rio de Janeiro (MAR) em 2017-2018. A primeira mostra nasceu da parceria com o Museu da Justiça (Rio de Janeiro) e o Museu do Índio em razão dos oficiais 450 anos da cidade do Rio. O título da exposição, todavia, evidencia a presença histórico-contemporânea dos indígenas na capital (e todo o território) fluminense, deslocando o olhar dos visitantes para a ideia de continuum - evidente contraposição aos discursos oficiais de extinção, sumiço, desaparecimento. Vale lembrar que oficialmente no fim do século XIX se decretou a inexistência dos indígenas no estado (FREIRE; MALHEIROS, 2009; SILVA, 2016). Autoridades estaduais, todavia, reconheceram a presença dos guarani na década de 1970, durante a construçáo da Rodovia Rio-Santos (regiáo sul fluminense).

Distinto dos demais projetos expositivos que realizamos e participamos, vale ressaltar a metodologia conceitual de Djá Guata Porã: 
Rio de Janeiro Indígena, sob a curadoria de Sandra Benites, José R. Bessa Freire, Clarissa Diniz e Pablo Lafuente. A mostra foi concebida por meio de um processo dialógico entre indígenas e especialistas de variadas áreas, construído em reunióes da equipe, encontros abertos ao público no museu e aldeias. Por meio da temática dos povos indígenas habitantes contemporaneamente no Rio - Puri, Pataxó, Guarani e os indígenas em contexto urbano - a exposição foi dividida em quatro núcleos (contemplando a diversidade acima mapeada) e cinco estaçóes apresentando "temas que atravessam épocas e povos, denotando sua relevância para a história cultural e de resistência dos povos indígenas: comércio, arte, educação, mulheres e natureza" (MAR, 2017a), todos assinados pelos próprios indígenas.

Abraçando e percorrendo todo o pavilhão de exposiçóes, a "cobra grande" serpenteava em ziguezagues dando vida à linha do tempo. Como nas narrativas orais dos povos do norte amazônico, seu corpo prenhe trazia informaçóes variadas acerca da população indígena brasileira no tempo e no espaço, enfatizando a diversidade cultural, linguística desses povos, o protagonismo, resistências e lutas ao longo dos séculos. Desse modo, a cobra/linha do tempo era:

Protagonista de narrativas da origem de vários povos, advertindo-nos, por meio dos mitos que traz consigo, de outras historicidades e futuros possíveis. Em sua trajetória, o réptil traça um caminho de destino incerto, construído como um processo potencialmente infinito, atravessado por lutas, retomadas, propostas e esperanças (MAR, 2017a).

Esperanças nesses tempos difíceis, no qual muitas sombras e incertezas pairam sob o futuro, especialmente dos povos indígenas.

\section{A REAÇÃO DOS ALUNOS, DO PÚBLICO}

Muitos alunos das licenciaturas, agora formados, ali nas escolas públicas ou particulares em que trabalham como professores, passaram 
a usar os livros Aldeamentos indígenas do Rio de Janeiro, Te mandei um passarinho e o Mainoî rapé de forma alternada, por considerarem que fazem circular, em linguagem acessível, conhecimentos produzidos pela academia para um público que de outra forma não possuía meios de deles se apropriarem. No entanto, não foi possível avaliar, de forma mais sistemática, como as informaçóes foram recebidas pelas crianças e pelos jovens. Isso porque não foram criados instrumentos para acompanhar a recepção de modo permanente e contínuo.

Quanto às exposiçóes criadas com livros ou a partir das informações neles contidas como "O Rio de Janeiro continua índio", indicadores, mesmo precários, permitem fazer algumas observaçôes sobre a reação do público, como nas ocasióes em que as exposiçóes foram acompanhadas de debates e palestras. Nesse caso, as perguntas vindas do auditório - muitas delas formuladas por escrito — foram quase sempre desencadeadas pelas imagens e objetos expostos, revelando a tensão entre os conhecimentos veiculados nas mostras e o grau de desinformação dos participantes. Por exemplo, as diferenças culturais, históricas e linguísticas entre os diversos povos indígenas, ressaltadas nos três livros e nas exposiçóes, contrariavam as imagens estereotipadas do indígena genérico (FREIRE, 2016), já internalizadas, do mesmo modo que os dados sobre os saberes e as artes indígenas conflitavam com a representação disseminada sobre o "atraso" dessas culturas. Dessa forma, é possível concluir que os livros e as exposiçóes contribuíram, no mínimo, para instaurar dúvidas ali onde existiam verdades sedimentadas e para aguçar a curiosidade do público, estimulando-o a refletir e a questionar alguns preconceitos e lugares comuns.

As reiteradas solicitaçóes das escolas, os espaços oferecidos pelas prefeituras e o tempo de permanência das mostras em cada lugar são também indicadores sensíveis do interesse que despertaram. No caso do município de Casimiro de Abreu, onde realizamos desde 2001 oficinas, seminários e algumas exposições que circularam em momentos diferentes, aplicou-se um questionário para avaliar o comportamento do público ou, pelo menos, de um segmento dele. Durante a II Jornada Fluminense de Cultura, o questionário foi preenchido por animadores culturais, artesãos, professores e gestores de cultura de vários municípios que participavam de uma oficina sobre a reinvenção do museu 
pelas comunidades populares e indígenas. As respostas, em geral, consideraram que a atividade continha informaçóes atualizadas e imagens bem contextualizadas, em linguagem clara e direta, contrapondo-as aos conhecimentos veiculados pela escola e pela mídia, considerados "insuficientes" ou até "ultrapassados".

O perfil do público - predominantemente, mas não exclusivamente escolar - sofreu pequenas variaçóes de uma exposição a outra, de acordo com a natureza delas e o lugar onde foram montadas. Os variados perfis de público são importantes por diversas razóes, entre elas na definição do discurso museológico elaborado para comunicar, informar, sensibilizar e capturar o visitante. Do ponto de vista quantitativo, é difícil calcular com precisão o número de visitantes, porque não houve um controle sistemático das pessoas que viram as mostras exibidas. Qualquer estimativa, portanto, deve ser encarada com muito cuidado. Feita essa ressalva, acreditamos que talvez não seja exagerado presumir que mais de 80 mil pessoas puderam ver ao menos uma das exposiçóes montadas especificamente nas escolas e municípios por onde circularam durante vários anos as nossas primeiras exposições.

A mostra Dja Guata Porá, por exemplo, foi vista por mais de 150 mil pessoas, vindas de regióes diversas do Brasil e do mundo. Caminharam no pavilhão de exposiçóes indígenas pertencentes a diversos povos (habitantes no Rio e outros estados), professores, alunos do ensino fundamental e médio de escolas municipais, particulares, graduandos e pós-graduandos, antropólogos, historiadores, linguistas, sociólogos, museólogos, pedagogos, jornalistas, artistas. A diversidade do público e o sucesso da exposição podem ser explicados não apenas pela beleza, singularidade e encantamento da mostra - com fotografias, objetos, instalaçóes e vídeos elaborados por e com os indígenas, todos abraçados pela impactante cobra grande - , mas também pela inclusão das discussóes apresentadas em Dja Guata Porá nos programas da Escola do Olhar do Museu de Arte do Rio, nas atividades do PROÍNDIO-UERJ, além das açóes (feira de arte indígena, encontros, cursos, residências, oficinas) previstas pela equipe curatorial da exposiçáo.

Vale destacar, assim, algumas atividades que tiveram como ponto de partida essa mostra: a mesa Diálogos sobre a Estação Mulheres em "Dja Guata Poră" — Rio de Janeiro Indígena, com a escritora 
Eliane Potiguara e a atriz Zahy Guajajara (parte do curso Mulheres, Arte e Ciências); o seminário Dja Guata Porã: Rio de Janeiro Indígena: Museus e Emergências Contemporâneas, que abordou os temas: museus e índios, cosmologias e demarcação dos territórios indígenas, com a participação de Elvira Espejo, Suzenalson Kanindé, Tamimi Borsatto, Ibã Huni Kuĩn, Edson Kayapó, Joênia Wapixana, Tonico Benites Guarani e Eloy Terena. Por último, o curso História do Rio de Janeiro: Dja Guata Porã/Rio de Janeiro indígena, voltado para discutir a linha do tempo (dividida em: tempo da autonomia, tempo da invasão, tempo da usurpação e o tempo das retomadas), contextualizando conceitos, períodos e acontecimentos que marcam e estabelecem transformações na vida e cultura dos povos indígenas.

O PROÍNDIO, por sua vez, também inseriu a mostra nas suas atividades. Por meio de seus pesquisadores, participamos de cursos, seminários, estimulando a ida de professores e alunos da UERJ e da UNIRIO ao MAR, realizando ainda aulas guiadas para estudantes de História, Antropologia, pós-graduandos em Propriedade Intelectual e os estudantes dos nossos cursos de línguas e culturas Guarani e Yorubá. As reaçôes e avaliaçóes, de modo geral, foram muito positivas tanto dos grupos que acompanhamos, quanto dos visitantes da exposição. Devido ao volume de informações e vídeos, diversos alunos retornaram outras vezes para absorver cada imagem, cada palavra, cada vídeo. É preciso dizer que o MAR não possuía instrumentos para quantificar o número de visitantes de suas mostras e tão pouco registrava suas opinióes. O setor de comunicação, todavia, realizava pesquisas gerais junto ao público para saber questôes diversas ligadas ao museu.

Durante a entrevista, o visitante deveria dizer o seu nome, dar uma nota (de 0 a 10) e informar a razão principal da avaliação. Assim sendo, foi possível ter um retorno dos visitantes brasileiros e estrangeiros. Dos entrevistados em julho e agosto, por exemplo, mais de 400 pessoas responderam que a exposição Dja Guata Porã foi o motivo principal da nota e, desse modo, avaliaram positivamente o MAR. A exposição, portanto, qualificou o museu e a mostra foi muito bem avaliada pelo público. Dja Guata Porá, pelo olhar daqueles que a viram, significou o "resgate da cultura dos índios", "el reconocimento de la historia indigena", "interesting exhibits on indigenous culture", "a diversidade, Rio 
mais indígena" (MAR, 2017b). Afinal, entre maio de 2017 e março de 2018 muitos rios indígenas desaguaram no MAR.

\section{BATENDO AS ASAS: CONSIDERAÇÕES FINAIS}

Nas últimas décadas, o Programa de Estudos dos Povos Indígenas, em parceira com diferentes instituiçóes, desenvolveu variadas ações no campo educacional com os intuitos de divulgar e valorizar a riqueza de saberes, práticas culturais e línguas indígenas, contribuindo para a formação de futuros docentes e cidadãos. Para cumprir nosso compromisso com esses povos e com uma educação transformadora, atuamos em duas frentes: desenvolvendo materiais didáticos e paradidáticos, destinados ao público pouco familiarizado com a temática - alunos, professores, leitores outros. Publicamos, desse modo, os livros: Aldeamentos Indigenas do Rio de Janeiro e Mainoî rapé: o caminho da sabedoria. Já a obra Te mandei um passarinho infelizmente continua no prelo. Todavia, centenas de passarinhos (arquivo digital) foram distribuídos em nossas atividades e hoje batem suas asas em quase todo o Brasil.

Por outro lado, atuamos em escolas públicas e particulares, universidades, museus e variados espaços expositivos ministrando palestras, cursos, oficinas, participando de seminários, encontros e montando exposições. Nosso objetivo é levar ao público uma reflexão sobre o lugar dos indígenas na sociedade brasileira, enfatizando o papel de agentes históricos que sempre foram. Além disso, buscamos desconstruir equívocos e refutar abordagens simplistas acerca dessas sociedades, estimulando a valorizaçáo, o respeito e a convivência com a diferença (ou diferenças) de perspectivas, línguas, maneiras de ser e viver no mundo. Uma rica diversidade que torna o Brasil ainda bastante singular nas Américas.

Olhando para o passado, para os 26 anos de atuação do PROÍNDIO-UERJ, enxergamos um caminho bastante consolidado pelo único programa de extensão universitária (não somente, pois atuamos nos campos ensino e pesquisa) público no Rio de Janeiro que se dedica integralmente aos povos indígenas (desde a sua criação em 
1992, no âmbito da ECO-92) aos dias atuais. Nossas publicaçóes têm estimulado pesquisas, seminários, atividades e seguem contribuindo para qualificar a discussão sobre o tema povos indígenas nas mais diversas escolas e universidades do estado. Desse modo, após uma década da Lei no 11.645/2008, podemos afirmar que o Programa de Estudos dos Povos Indígenas e seus parceiros muito têm contribuído para a implementação da referida lei no estado fluminense, seja pelo desenvolvimento de bibliografia especializada, seja através por necessários projetos expositivos.

Sobre as exposições, é possível concluir que constituíram uma forma insubstituível de comunicação, pelo que foi dito e pelo público atingido, quase sempre à margem do circuito acadêmico. As mostras realizadas não se limitaram ao universo escolar — alunos, pais de alunos e professores. Também alcançaram um público especializado (principalmente nos casos das exposiçóes O Rio de Janeiro Continua Índio e Dja Guata Porā), na medida em que dialogaram com outras formas de comunicação usadas pelo PROÍNDIO e seus parceiros, a saber: redes sociais, flyer, sites, encontros, seminários e a militância. Nos nossos primeiros projetos expositivos, todavia, notadamente artigos publicados em revistas especializadas e participaçóes em congressos nacionais e internacionais aproximaram as mostras do público acadêmico.

Todas elas foram montadas de forma articulada com outros projetos de pesquisa e de extensão, repercutindo nas atividades de ensino. Seu raio de ação foi ampliado, graças a parcerias com outras universidades, organizaçóes governamentais e não governamentais, entidades de várias confissóes religiosas, sindicatos, especialmente os de professores e, sobretudo, com organizaçóes indígenas. Um olhar crítico sobre elas revela que constituíram um espaço não só para mostrar, mas também um espaço para pensar e até para errar, na medida em que estiveram abertas para o ensaio e para propostas inconclusas.

Nesses dez anos da Lei no 11.645, portanto, desejamos que o Brasil possa respeitar e viver com a diversidade de perspectivas, pensamentos, culturas, línguas existentes em seu território, permitindo assim voos outros do passarinho. Que suas asas continuem batendo, anunciando a boa nova, espalhando a sabedoria dos povos indígenas. 


\section{REFERÊNCIAS}

BRASIL. Lei $\mathrm{n}^{\circ}$ 11.645. Altera a Lei $\mathrm{n}^{\circ}$ 9.394, de 20 de dezembro de 1996, modificada pela Lei $\mathrm{n}^{\circ} 10.639$, de 9 de janeiro de 2003, que estabelece as diretrizes e bases da educaçấo nacional, para incluir no currículo oficial da rede de ensino a obrigatoriedade da temática "História e Cultura Afro-Brasileira e Indígena”. Diário Oficial da República Federativa do Brasil, Brasília, 2008.

DIAS, O. O índio no Recôncavo da Guanabara. Revista do Instituto Histórico e Geográfico, Rio de Janeiro, n. 399, p. 399-461, 1998.

FREIRE, J.R.B. Apresentação. In: FREIRE, J.R.B. Mainơi Rapé: o caminho da sabedoria. Rio de Janeiro: Iphan / EdUerj, 2009a.

FREIRE, J.R.B. As primeiras imagens da Conquista. Rio de Janeiro: EdUerj, 1992.

FREIRE, J.R.B. Cinco ideias equivocadas sobre os índios. Repecult, Rio de Janeiro, v. 1, n. 2, p. 3-23, 2016. Disponível em: shttp://www.ufrrj.br/SEER/index. php?journal=REPECULT\&page $=$ article \&op $=$ view \&path $\% 5 B \% 5 D=3529>$. Acesso em: 13 maio 2018.

FREIRE, J.R.B. Os indios em arquivos do Rio de Janeiro. Rio de Janeiro: EdUerj, 1995. v. 1.

FREIRE, J.R.B. Os indios em arquivos do Rio de Janeiro. Rio de Janeiro: EdUerj, 1996. v. 2.

FREIRE, J.R.B. Tradução e interculturalidade: o passarinho, a gaiola e o cesto. Alea: Estudos Neolatinos, Rio de Janeiro, v. 11, n. 2, p. 321-340, 2009b. Disponível em: $\quad$ http://www.scielo.br/scielo.php?script=sci arttext\&pid=S1517-106X2 009000200010\&lng=pt\&tlng=pt $>$. Acesso em: 13 maio 2018. http://dx.doi. org/10.1590/S1517-106X2009000200010

FREIRE, J.R.B.; MALHEIROS, M.F. Aldeamentos Indígenas do Rio de Janeiro. Rio de Janeiro: EdUerj, 2009.

MACIEL, I. et al. (orgs.). Te mandei um passarinho: prosas e versos de índios no Brasil. Brasília: MEC, 2007.

MAGAlHÁES, J.V.C. de. O Selvagem. Rio de Janeiro: Typographia da Reforma, 1876.

MONTEIRO, J. Guia de fontes para a história indigena e do indigenismo em arquivos brasileiros. São Paulo: EdUSP/Fapesp, 1994. 
MUNDURUKU, D. A literatura indígena não é subalterna. 2018. Disponível em: $\quad$ http://www.itaucultural.org.br/a-literatura-indigena-nao-e-subalterna $>$. Acesso em: 15 maio 2018.

MUSEU DE ARTE DO RIO (MAR). Planilha conteúdo Dja Guata Porã. In: MUSEU DE ARTE DO RIO (MAR). Arquivo do Museu de Arte do Rio. Rio de Janeiro: MAR, 2017a.

MUSEU DE ARTE DO RIO (MAR). Programação do Seminário Dja Guata Porã: Rio de Janeiro Indígena - Museus e Emergências Contemporâneas. Rio de Janeiro: MAR, 2017b. Disponível em: <https://www.revistamuseu.com.br/site/ br/noticias/nacionais/2925-02-06-2017-museu-de-arte-do-rio-inaugura-djaguata-pora-l-rio-de-janeiro-indigena.html>. Acesso em: 20 jun. de 2018.

PROGRAMA DE ESTUDOS DOS POVOS INDÍGENAS (PROÍNDIOUERJ). Encontrei um passarinho. Rio de Janeiro: EdUerj, 2011.

PROGRAMA DE ESTUDOS DOS POVOS INDÍGENAS (PROÍNDIOUERJ). Relatório anual de atividades. In: PROGRAMA DE ESTUDOS DOS POVOS INDÍGENAS (PROÍNDIO-UERJ). Arquivo do Pró Índio-UERJ. Rio de Janeiro: EdUerj, 1999.

RICARDO, C.A. "Os índios" e a sociedade nativa contemporânea no Brasil. In: SILVA, A.L.; GRUPIONI, L.D. (orgs.). A temática indígena na escola: novos subsídios para professores de $1^{\circ}$ e $2^{\circ}$ graus. Brasília: MEC/MARI/UNESCO, 1995. p. 29-60.

SILVA, A.L.; GRUPIONI, L.D. (orgs.). A temática indígena na escola: novos subsídios para professores de $1^{\circ}$ e $2^{\circ}$ graus. Brasília: MEC/MARI/ UNESCO, 1995.

SILVA, A.P. da. O Rio de Janeiro continua indio: território do protagonismo e da diplomacia indígena no século XIX. 360f. Tese (Doutorado em Memória Social) Universidade Federal do Estado do Rio de Janeiro, Rio de Janeiro, 2016.

TELLES, L.S. (org.). Maino’i Rapé: o caminho da sabedoria. Rio de Janeiro: Iphan/CNFPC/EdUerj, 2009.

\section{NOTAS}

1. Entre os anos de 2008 e 2016, por meio do projeto de extensão A Imagem dos Índios na Escola: os Índios no Rio de Janeiro, o Programa de Estudos dos Povos Indígenas, em parceria com a Secretaria de Educação do Estado do Rio de Janeiro (SEEDUC), 
secretarias de educação municipais, Museu do Índio/RJ, a Fundação Nacional do Índio (FUNAI) e associaçóes indígenas dos Guarani, realizou estudos, debates, cursos, oficinas, exposiçôes, seminários, encontros, pesquisas e intercâmbios sobre a temática indígena, visando a formaçáo de profissionais das redes de ensino, alunos e pessoas que compóem a comunidade escolar.

2. Nessa entidade, atuamos respectivamente desde 1992 e 2007.

3. A exposiçăo foi concebida para o público da 6a UERJ Sem Muros (1995) e do I Congresso de Extensão das Universidades Públicas, realizado em São Paulo no ano de 1997.

4. O manuscrito foi encontrado no Arquivo Nacional do Rio de Janeiro pela equipe de pesquisadores do Programa de Estudos dos Povos Indígenas, no âmbito do projeto Guia de Fontes. Foi reproduzido na íntegra no livro Aldeamentos Indigenas do Rio de Janeiro.

Recebido em 6 de fevereiro de 2019.

Aprovado em 9 setembro de 2019. 